\title{
ТЕОРИЯ ДРАМЫ
}

DOI $10.37386 / 2305-4077-2021-1-56-66$

\author{
Л. Г. Тютелова ${ }^{1}$ \\ Самарский национальный исследовательский университет имени \\ академика С. П. Королева

\section{«КОММЕНТАТОР» КАК ОРГАНИЗАТОР КОММУНИКАТИВНОГО СОБЫТИЯ В ПЬЕСЕ АСИ ВОЛОШИНОЙ «ШИНЕЛЬ ГОГОЛЯ»}

Статья посвящена проблеме коммуникативного события в драме. В исследовании текст пьесы рассматривается как пространство взаимодействия сознаний автора, читателя и героя. Автор статьи доказывает, что одним из условий организации коммуникативного события становится появление «комментатора» - ремарочного субъекта, а итогом раскрытие особенностей этических и ценностных позиций современного драматурга и его читателя. В работе определяются особенности «комментатора», от которых зависит его роль организатора коммуникативного события. Материалом исследования являются пьеса петербургского драматурга Аси Волошиной «Шинель Гоголя» и спектакли Челябинского театра драмы имени Наума Орлова и петербургского театра «ЦЕХЪ».

Ключевые слова: коммуникативное событие, автор, читатель, ремарочный субъект, ремарка, комментатор.

\author{
L. G. Tyutelova
}

Samara National Research University

«COMMENTATOR» AS AN ORGANIZER

OF A COMMUNICATIVE EVENT IN ASYA

VOLOSHINA〉S PLAY «GOGOL〉S OVERCOAT»

The article is devoted to the problem of a communicative event in the drama. In the study, the text of the play is considered as a space of interaction between the minds of the author, reader and hero. The author of the article proves that one of the conditions for organizing a communicative event is the emergence of a "commentator" - a stage directions subject, and the result is the detection of specific ethical and value positions of the modern playwright and their reader. The work defines the features of the «commentator» which their role as an organizer of a communicative event depends on. The research material is the play by the Petersburg playwright Asya Voloshina «Gogol's Overcoat» and the performances of the Nahum Orlov Drama Theatre (Chelyabinsk) and the St. Petersburg theater «TSEKH».

Key words: communicative event, author, reader, stage directions subject, stage directions, commentator..

1 Лариса Геннадьевна Тютелова, доктор филологических наук, доцент, заведующий кафедрой русской и зарубежной литературы и связей с общественностью Самарского университета (Самара). 
В работах последнего времени достаточно часто возникает вопрос о формах авторского присутствия в текстах пьес (см. работы О. В. Журчевой [Журчева, 2001], О. С. Наумовой [Наумова, 2009], У. А. Копенкиной [Копенкина,2011], Е. В. Титовой [Титова, 2019] и других). При этом во многих исследованиях не обращают внимание на то, с какой целью драматург в современной пьесе стремится обозначить свое присутствие в драматическом событии, и самое важное - каковы итоги реализации авторского замысла. Ответ на эти вопросы и есть цель данной работы.

Первое, на что стоит обратить внимание, мир современной драмы - мир, представляющий своего творца-драматурга, на чем стали настаивать авторы уже в конце XVIII века. Так, А. С. Пушкин в 1830-м году высоко оценил погодинскую «Марфу Посадницу» за то, что ее создатель «писал свою трагедию вследствие сильного внутреннего убеждения, вполне предавшись независимому вдохновению, уединясь в своем труде» [Пушкин, 1964, т.VII, с. 217-218].

И эта позиция в начале XXI столетия остается неизменной. Главный герой проводимого исследования - Ася Волошина, петербургский драматург, чьи пьесы с успехом идут в России и за ее пределами, в одном из своих интервью признается: «Я бы не слишком доверяла персонажам: в любой пьесе, даже в классической, они не носители истины, они могут заблуждаться - автор ведь дробит себя на героев. Персонаж под своим углом видит узкую часть картины авторского мира. Авторский мир, в свою очередь, тоже является каким-то взглядом под каким-то ракурсом на мир как таковой (подчеркнуто мной.- Л.Т.)..» [Волошина, 2018]. Таким образом, авторский мир - это мир, сущностную причастность к которому автор не только осознает, но и показывает читателю с помощью уже обнаруженных исследователями форм авторского присутствия в драме.

Второй важный момент заключается в том, что современные драматурги не расширяют возможности драмы по «вхождению» в ее мир автора, а меняют содержание ее традиционных форм. В частности, переводят паратекст в разряд основного текста и выводят на первый план фигуру комментатора, чей голос звучит в ремарке. Ж. Женетт замечает: «Паратекст есть такой аксессуар, посредством которого текст становится книгой, и она как таковая предстает перед читателем. При этом речь идет не столько о барьере или непроницаемой границе, сколько о пороге, о некоторой “неопределенной зоне” между внутренним и внешним, у которой опятьтаки нет твердой границы ни изнутри, со стороны текста, ни снаружи, со стороны дискурса действительности о тексте» [Genette, 2001, s.10] (пер. Н. Т. Рымаря).

Следовательно, паратекст - это способ обозначения автором эстетической границы как места его пребывания. Именно благодаря этой границе обнаруживаются напряженные отношения в субъектной сфере произведения.

В драме автор обозначает пределы своего мира тем текстом, где он может говорить прямо-от своего лица - и не «входить» в пространство события-названием пьесы, посвящением, афишей и т.п. На том же пределе, то есть на границе, находится и тот, чей голос звучит в авторской ремарке. Но, как показывает опыт русской драмы уже XIX столетия, ремарка - это не прямое авторское высказывание. Субъект, чей 
голос звучит в ремарке, сродни романному повествователю. Он свободно входит в мир драматического события, оказывается рядом с героем и получает возможность, сохраняя собственные позиции видения и оценивания, комментировать читателю происходящее. Поэтому можно предположить, что роль образа «комментатора» не ограничивается обозначением «предела» авторского мира. Его фигура, возникающая в сознании читателя рядом с фигурой драматического героя, создает условия для коммуникации, благодаря которой специфика индивидуального мира драматурга открывается читателю. При этом стоит напомнить, что комментатор начинает играть роль «организатора» диалогических отношений автора, героя, читателя, выявляющих личностные границы каждого участника диалога, только в условиях новой поэтики - поэтики художественной модальности, как ее называет С. Н. Бройтман [Бройтман, 2001, с. 258].

В паратексте современной драмы появляются очень разные варианты «комментатора». Рассмотрим один из них на примере пьесы «Шинель Гоголя», созданной Асей Волошиной. Пьеса появилась в результате инициативы Челябинского театра драмы имени Наума Орлова, заказавшего инсценировку гоголевской «Шинели» петербургскому драматургу.

Как заметил Андрей Пронин в «Экране и сцене»: «Пьеса, получившаяся в итоге,- нечто большее, чем техническое приспособление прозы Гоголя к потребностям театра. Волошина не только попыталась преодолеть густые театральные штампы, наросшие на инсценировках “Шинели”, но также решилась снабдить гоголевский сюжет культурным конвоем из области так называемого “петербургского текста". “Шинель” Волошиной - “открытое произведение” (термин Умберто Эко), перелагающее Гоголя с интертекстуальными сносками на полях: тут аукаются “Невский проспект”, “Страшная месть”, “Вий”,- и Пушкин с его “Медным всадником” (Акакий попадает на похороны Евгения), и Блок с “ветром на всем белом свете”, и Андрей Белый. Присутствуют даже не петербургские Булгаков, Чехов и... “Макбет” Шекспира» [Пронин, 2017, http:// screenstage.ru/?p=6435].

Все петербургские и не/петербургские тексты существуют в едином пространстве авторского сознания, по воле которого они и взаимодействуют на сцене. Точнее, несколько иначе, если учитывать, что сцена - место реализации себя не драматургом, а режиссером как своеобразным читателем авторского текста.

Собственно, это отмечает и сама Волошина. Для нее заметным явлением творческой биографии стала постановка на сцене МХТ им. А. П. Чехова «Человек из рыбы», осуществленная Юрием Бутусовым (премьера 7 июля 2018 года). И в комментариях драматурга есть такое признание: «Когда я увидела на сцене МХT свой мир. Он же - одновременно, но независимо - был миром Юрия Бутусова» [Исмаилова, 2020, https://www.sobaka.ru/entertainment/theatre/111001]. Отсюда благодаря работе режиссера мы можем судить не только о коммуникационных механизмах, но и о результатах диалога читателя с автором. 
Драматург, взгляд на пьесу которого и показывается на сцене, становится своеобразным исследователем жизни: «он тот, кто по каким-то причинам решил потратить свою жизнь на исследование реальности средствами искусства. Почти наверняка он каких-то результатов в этом достиг» [Енина, 2017, http://www.zebro.ru/ asya-voloshina].

Как показывают пьесы Волошиной, чаще всего она обращается к своим современникам с вопросом «почему не живется»? Ей интересен и человек, который задается этим вопросом (такое ощущение, например, оставила «акция» Юрия Бутусова в театре им. Ленсовета в 2016 году, когда режиссер прочитал пьесу Волошиной «Мама» [Ким, 2016, http://ptj.spb.ru/blog/pust-vsegda-budu-ya]).

Ей интересно и то, что противостоит человеку и не дает ему «жить». В «Человеке из рыбы», например, это «некий эмиссар мрака, какая-то часть силы, которая хочет зла и совершает зло. Причем еще с налетом пошлости и серости. Русский чорт еще с гоголевских времен пошл» [Волошина, 2018, https://mnogobukv. hse.ru/news/225501993.html]. Это «темное», определяющее существование человека, как предположила Юлия Зу, «нечто женское, глубинное, видимо, жившее в самой Асе Волошиной неожиданно становится главным персонажем» [3y, 2019, http://musecube. org/otchet/otchet-theatre/chelovek-iz-ryby-v-mht-sneg-na-karavannoj-i-vse-vse-vse/?fbcli $\mathrm{d}=$ IwAR1f7ycBu65kjxBxCj2SX4TIcOvreYJj65Ut3EgR9NFUBFEz4Qf9WtoovGU].

Но для разных режиссеров при постановке одной и той же пьесы Волошиной актуальной оказывается лишь та или иная тема. Например, в петербургском театре «ЦЕХЪ» режиссер Виталий Дьяченко в спектакле по «Шинели Гоголя» ведет свой разговор с публикой «о всё том же гоголевском маленьком человеке в большом, но безлюдном городе» [Шудегов, 2018, https:/pluggedin.ru/op/recenziya-na-spektaklyshinely-gogolya-predpremyera-v-teatr-cehy-piter-kromeshnyy-13996]. В челябинском спектакле конфликт «из социальной плоскости сразу и бесповоротно переведен в метафизическую» [Пронин, 2017, http://screenstage.ru/?p=6435].

Возможность видеть в качестве основной ту или иную тему пьесы предоставляется самим драматургом посредством комментатора. Его речь, как речь того, чей голос слышится в ремарке,- драматический вариант речи повествователя. Автор благодаря ремарке напрямую обращается к читателю, вовлекая его в драматический мир как своего собеседника:

АКАКИЙ. Что?

- Ничего. То-то и оно, что ничего. Пустота... лепота...

(nоёт). Я в дорогу моряку

Дам в подруги грусть-тоску,

Чтоб, скучая, ни на час

Не смыкал он ночью глаз...

Кратко сказать, земля, прах, тень и ничтожная пустоша - всё то одно. А город что город?.. Ну, всё. Зелёный.

(Очень буднично и парадоксально. Для нас - как будто, да, про светофор. Но нет, почудилось (подчеркнуто мною.- Л.Т.).)

- Зелёный?? [Волошина, 2016, http://mythos.spb.ru/?p=19]. 


\section{Или еще один пример:}

Кругом раскинулась и воцарилась идея Петербурга. Чернильная вода. Чернильное пятно. Некуда им. Они здесь. Коренные жстели, отпрыски болот, пусть и нетвёрдо видные глазу. <...> Но мы отвлеклись (подчеркнуто мною.Л.T.). [Волошина, 2016, http://mythos.spb.ru/?p=19].

При этом языковые особенности ремарки свидетельствуют о том, что история разворачивается благодаря активной позиции ремарочного субъекта, обладающего своей индивидуальной позицией видения и понимания того, что происходит.

\section{Например:}

Подсюсюкивая, ровно речь о дитяте, извлекает Лиио-чиновника, будто бы на минутку прикорнувщего. Чиновник тут же принимает вид весьма почтенный.

Две ведьмы ловят Петровича и встряхивают, будто куклу. Он, кажется, приходит в состояние [Волошина, 2016, http://mythos.spb.ru/?p=19].

«Ровно речь о дитяте», «будто бы на минутку прикорнувшего», «будто куклу», «кажется» - слова и сочетания слов используются автором именно для того, чтобы было видно: ремарка не просто фиксирует действие, не сопровождаемое словами персонажей, а представляет это действие как кем-то увиденное и воспринятое.

Но стоит понять, что важен не сам факт обращения, а то, как и с чем к читателю обращается через своего комментатора автор.

Например, важно, что помимо читателя в поле зрения комментатора попадают и действующиелица пьесы. Итем самым устанавливается контакт автора, читателя и героя. Комментатор сближает их благодаря продемонстрированной способности говорить на языке «другого».

Каменный город утвердился, но что делать пузырям земли? Что делать тем созданиям и исчадиям, коие жили здесь с основания мира? Нешто «эмигрировать»? [Волошина, 2016, http://mythos.spb.ru/?p=19].

Во фразе «нешто “эмигрировать”» очевидно звучат интонации действующих лиц пьесы.

Эта особенность комментатора быть «другим» и в то же время указать на дистанцию между собой и этим другим - обозначение основных характеристик современной художественной коммуникации. Она не требует отождествления себя с персонажем, но требует его понимания через собственный опыт: жизненный, культурный, интеллектуальный и т.п.

При этом, понимая другого, читатель открывает путь и для понимания самого себя. У Волошиной главной особенностью героя становится его подвижность. Мы наблюдаем чреду преображений. Например, женских образов. Это жена Петровича, квартирная хозяйка Мавра, матушка Акакия. Они названы ипостасями. (Кстати, это позволяет при желании режиссера на сцене воплотить их образ одной актрисе.) 
Конечная точка женского преображения у Волошиной - подруга жизни Башмачкина - шинель, которая и спасает, и морочит, и приводит к гибели:

АКАКИЙ. <..> Вот-с вам и юс, вот-с вам и ерь. Вот-с как. Подруга. Шинель. Хоть приснилась бы. То-то же... (Акакий Акакиевич засылает.) [Волошина, 2016, http://mythos.spb.ru/?p=19].

В итоге женщина в мире Волошиной и морочит, и спасает, и приводит к гибели. И ни одна из ролей не может ни заместить собой другую, ни исчерпать сущность женщины, как ее понимает драматург.

Преображения волошинских героев возникают благодаря тому, что, подобно комментатору, герои говорят на языке другого. В первую очередь - это бесы, чьи козни влияют на судьбу города и его жителей. Для создания их образа используются слова «гоголевских повестей», что создает ощущение, что бесы дают волю слову горожан, заставляют звучать многоголосый Петербург:

То принимают вид чиновников, а то и дам (а иногда, будто самая одежда на вешалках в их руках разговаривает) и всячески его [Башмачкина.Л.Т.] ловят.

- Господа, а знаете ли, что подублен хвост?

- Хвост?

- Хвост?

Вертятся, будто проверяя, не выпрастался ли из-под одежды их собственный [Волошина, 2016, http://mythos.spb.ru/?p=19].

На языке другого говорит и Значительное лицо. Свое сценическое существование в пьесе Волошиной оно начинает с произнесения слов Пролога «Петербурга» Андрея Белого. Текст символистского романа воспроизводится с купюрами, а в финале произносится, согласно ремарке, «скомкано» [Волошина, 2016, http://mythos.spb.ru/?p=19]. И только когда речь произнесена полностью «значительное лицо может дать свою волю» [Волошина, 2016, http://mythos.

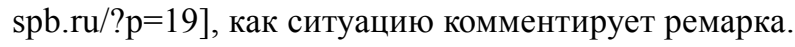

Интересно, что, воссоздавая петербургский текст русской литературы, и драматург, подобно герою (или герой, подобно ему), дает себе волю за пределами цитаты, на их стыках, при переходе от одной к другой. Следовательно, предлагая читателю через опыт другого открыть границы собственной индивидуальности, автор и для себя выбирает тот же путь.

При таком поиске себя и при таком обозначении собственного понимания мира обнаружить его прямое выражение в пьесе нельзя, как нельзя и доверять словам комментатора. Недаром в ремарках обнаруживаются ироничные интонации: это своеобразные моменты передачи позиции другого и отстранения от нее:

Акакий Акакиевич только моргает. Он, может быть, как был, развоплощённый, беленький, в белье. Он не верит. Не ждал, что так скоро. Всего-то какой-то год [Волошина, 2016, http://mythos.spb.ru/?p=19]. 
Это заставляет читателя и идти вслед за ремарочным субъектом, открывать авторскую тему, напрямую названную, и в то же время не верить, искать альтернативу, обнаруживать варианты и выбирать актуальный для себя. Иными словами, ремарке Волошиной, даже если звучащий в ней голос обнаруживает невероятную осведомленность о герое, его характере или событии (Впрочем, в этом вопросе на Акакия Акакиевича положиться полностью нельзя, ибо он особенной приметливостью, как известно, не отличался (подчеркнуто мною. Л.T.) [Волошина, 2016, http://mythos.spb.ru/?p=19]), до конца доверять нельзя. Автор предоставляет режиссеру как читателю своей пьесы свободу - свободу выбора темы и свободу ее воплощения как открытие и выражение себя:

Обсыпает его опилками или какой-то другой ветошью (вылелено мною.Л.Т.) [Волошина, 2016, http://mythos.spb.ru/?p=19].

Входит Жена Петровича, неся самовар или другой агрегат, напускаюший nару (вылделено мною. - Л.Т.) [Волошина, 2016, http://mythos.spb.ru/?p=19].

Гроб или по христианскому обычаю опускают в яму, или по басурманскому пускают в реку (выделено мною.- Л.Т.). Прощуаются [Волошина, 2016, http://mythos.spb.ru/?p=19].

Это свободой и пользуются режиссеры.

Так, Денис Хуснияров в челябинскойпостановкерассказывает «опитерской болотной нечисти, приспособившейся к градостроительным новациям Петра Великого, нашедшей способ прикинуться людьми, но неустанно морочащей и изводящей хилых петербуржцев. Нечисть представлена в спектакле троицей ведьм. Их роли исполняют вполне брутальные мужчины - Александр Бауэр, Михаил Гребень, Владислав Коченда, время от времени они перекидываются репликами из “Макбета". Здешние ведьмы с легкостью перевоплощаются в шамкающих старух-сплетниц, потом в надменных чиновников - сослуживцев Акакия, могут обернуться продавцами мороженого, а могут превратиться в зевак, собравшихся на похоронах (тележка с мороженым легко трансформируется в похоронные дроги). Способны предстать лодочниками и следить за Акакием с веслами наперевес - и даже перевоплотиться в духовных лиц» [Пронин, 2017, http://screenstage.ru/?p=6435].

В итоге челябинский спектакль - рассказ о мировом хаосе, который проявляется в утрате героями личностных границ, что и приводит к постоянной метаморфозе образов, обнаруживает ее причины. И самая знаковая ситуация случай Башмачкина, которого, согласно ремарке «вытряхивают из иинели». После этого Марфа, хозяйка квартиры Башмачкина, «поднимает из воды Акакия. Он - тряпичная кукла», не способная произнести ни слова.

Правда, он и до этого не был многословным:

АКАКИЙ. Право... Того. Фета рцы слово.

- А барин никак титулярный советник? Глядите, ему пятьдесят, а он всё ещё титулярный. Титулярный титулярным и помрёт. 
АКАКИЙ. Покой веди червь иже ижица [Волошина, 2016, http://mythos. spb.ru/?p=19].

ГОЛОС АКАКИЯ. Больше двух рублей того... не давать. Живите, добро, юс [Волошина, 2016, http://mythos.spb.ru/?p=19].

АКАКИЙ. Экая... экая такая площадь. Очень-на громадна. Эко... Темень... Точное море... Нет, лучше не глядеть. Живите, мыслите, слово, твердо... Совсем не глядеть [Волошина, 2016, http://mythos.spb.ru/?p=19].

$\mathrm{B}$ репликах Башмачкина преобладают междометия и названия букв славянского алфавита, которые очерчивают границы мира Башмачкина. Именно такова роль алфавита, как об этим говорят исследования медиевистов. Нет букв - границы мира стираются и воцаряется хаос.

А поскольку, рассматривая тему мирового хаоса, Волошина актуализирует и тему маленького человека, сохраняя гоголевские образы чиновников, значительного лица, то у режиссера появляется возможность выбрать в качестве основной социальную тему - тему судьбы человека и его ответственности за эту судьбу. Так и поступает режиссер петербургского театра Виталий Дьяченко. В его спектакле «вести» действие будут бесы, при создании образов которых важна их способность принимать облик жителей Петербурга, как о том говорит первая ремарка, предлагающая читателю увидеть бесов в облике тех, кому могут принадлежать звучащие голоса:

На петербургской площяади, ещё пустынной по причине раннего утра, в тех обличиях, каковые угодно представить зрителю,- три ведьмыл.Петрербурх...- Петербурх...- Жизнь, право, тонкая и политичная.- Кеатры...Собаки тебе танцуют [Волошина, 2016, http://mythos.spb.ru/?p=19].

При чем, Волошина не сразу помогает читательскому воображению. Лишь в середине пьесы появляются ремарки, четко фиксирующие преображения беса, хотя и в этом случае конкретные черты героя не фиксируются:

Ошалельй, Акакий Акакиевич не двигается с места. Мимо две ведьмы в картинном трауре несут гроб. Третья подходит к нему, тоже приняв облик жителя [Волошина, 2016, http://mythos.spb.ru/?p=19].

Таким образом, особенности волошинской ремарки активизируют воображение и позволяют режиссеру «расширить» образ жителя Петербурга. В спектакле Виталия Дьяченко бесы - это и те, кто нашептывает «портному Петровичу, чтобы тот взял за работу дороже; и гробовщики, рассказывающие незадачливому Акакию его участь на примере другого недавно скончавшегося. И эти дьявольские дУхи города будут бить героя шинелями, тихонько посмеиваться проказам из своих ям, пока в конце сами же не сдернут с него на пустыре новую шинель, безупречно сшитую Петровичем» [Шудегов, 2018, https://pluggedin.ru/op/recenziya-na-spektakly-shinely-gogolya-predpremyerav-teatr-cehy-piter-kromeshnyy-13996]. Поэтому получается, что все герои принимают активное участие в судьбе Башмачкина, но важно, как он сам реагирует на это влияние. 
Если подвести итог - каждый из режиссеров через волошинский текст реализует себя, своей видение актуальных проблем современности, о которых и говорит их спектакль. Предоставила им такую возможность автор. И помог ей в этом ее комментатор.

Он оказался организатором коммуникативного события - события встречи сознания автора, с его позицией видения происходящего, и читателя, обладающего собственным опытом. Многоликость комментатора, его обращенность и к читателю, и к герою, способность быть другим и не быть им, отстраняться от «другого», предлагать свои решения, но и не настаивать на них - эти качества комментатора и позволили сыграть ту роль, которая ему отведена Волошиной при организации коммуникативного события.

\section{СПИСОК ЛИТЕРАТУРЫ}

Бройтман, С. Н. Историческая поэтика / С. Н. Бройтман.-Москва: Изд-во РГГУ, 2001.-320 c.

Волошина, А. «Драматургия - это опрокинутый психоанализ»: О жизни после осуществления мечты, акустическом театре и культурной памяти / А. Волошина // Многобукв. Всё о creative writing / Новости. 9 октября 2018.-URL: https://mnogobukv.hse.ru/news/225501993.html (дата обращения: 1.12.2020).

Волошина, А. Шинель Гоголя. - 2016. - URL: http://mythos.spb.ru/?p=19 (дата обращения: 5.11.2020).

Енина, К. Ася Волошина: «Мне кажется, в пьесе, романе, рассказе не должно быть ни одного случайного, неточного слова»/ К. Енина // Zebro.ru.26.09.2017.-URL: http://www.zebro.ru/asya-voloshina/ (дата обращения: 5.11.2020).

Журчева, О. В. Формы выражения авторского сознания в «Новой драме» рубежа Х1Х-XX веков / О. В. Журчева // Культура и текст.-2001.-С. 138-151.

Зу, Ю. “Человек из рыбы” в МХТ: Снег на Караванной и все-всевсе / Ю. Зу // MUSECUBE: территория творческой свободы.- 12.03.2019.URL: $\quad$ http://musecube.org/otchet/otchet-theatre/chelovek-iz-ryby-v-mht-sneg-nakaravannoj-i-vse-vse-vse/?fbclid=IwAR1f7ycBu65kjxBxCj2SX4TIcOvreYJj65Ut3Eg R9NFUBFEz4Qf9WtoovGU (дата обращения: 01.12.20202).

Исмаилова, А. Как Ася Волошина стала главным российским драматургом новой школы / А. Исмаилова // Спб.Собака.ru.- 2020.- URL: https://www.sobaka. $\mathrm{ru} /$ entertainment/theatre/111001 (дата обращения: 5.11.2020).

Ким, А «Пусть всегда буду я...» / А. Ким // Петербургский театральный журнал.- 18.12.2016. Комментарии. - URL: http://ptj.spb.ru/blog/pust-vsegda-buduуа/ (дата обращения: 5.11.2020).

Копенкина, У. А. Проблема автора в драматургических текстах Н. В. Гоголя: автореф. дис... канд. филол. наук. Специальность:10.01.01 / У. А. Копенкина.Саратов, 2011.-24 c. 
Наумова, О.С. Формы выражения авторского сознания в драматургии конца XX - начала XXI вв. (на примере творчества Н. Коляды и Е. Гришковца): автореф. дис. ... канд. филол. наук. Специальность:10.01.01 / О. С. Наумова.Самара, 2009.- 18 c.

Пронин, А. Страшная сказка о Петербурге / А. Пронин // Экран и сцена.2017. - 31 марта. - URL: http://screenstage.ru/?p=6435 (дата обращения: 5.11.2020).

Пушкин А. С. О народной драме и драме «Марфа Посадница» / А. С. Пушкин. Полное собрание сочинений в 10 т. T.VII: Критика и публицистика.Москва: Наука, 1964.- С. 211-221.

Титова, Е. В. Драматургический паратекст: к постановке проблемы / Е.В. Титова // Вестник РГГУ. Серия: Литературоведение. Языкознание. Культурология.-2019.- № 2.- С. 30-40.

Шудегов, И. Питер кромешный: Рецензия на спектакль «Шинель Гоголя». Предпремьера в театр «ЦЕХЪ» / И. Шудегов // Plugged In.- 16.12.2018.- URL: https://pluggedin.ru/op/recenziya-na-spektakly-shinely-gogolya-predpremyera-v-teatrcehy-piter-kromeshnyy-13996 (дата обращения: 01.12.2020).

Genette, G. Paratexte. Das Buch vom Beiwerk des Buches / G. Genette.Frankfurt/ M: Suhrkamp, 2001.-401 s.

\section{REFERENCES:}

Brojtman, S. N. Istoricheskaya poetika / S. N. Brojtman.- Moskva: Izd-vo RGGU, 2001.-320 s.

Enina, K. Asya Voloshina: «Mne kazhetsya, v p'ese, romane, rasskaze ne dolzhno byt' ni odnogo sluchajnogo, netochnogo slova» / K. Enina // Zebro.ru.-26.09.2017.URL: http://www.zebro.ru/asya-voloshina/ (data obrashcheniya: 5.11.2020).

Ismailova, A. Kak Asya Voloshina stala glavnym rossijskim dramaturgom novoj shkoly / A. Ismailova // Spb. Sobaka.ru.-2020.- URL: https://www.sobaka.ru/ entertainment/theatre/111001 (data obrashcheniya: 5.11.2020).

Kim, A «Pust' vsegda budu ya...»/ A. Kim // Peterburgskij teatral'nyj zhurnal.- 18.12.2016. Kommentarii http://ptj.spb.ru/blog/pust-vsegda-budu-ya/ (data obrashcheniya: 5.11.2020).

Kopenkina, U.A. Problema avtora v dramaturgicheskih tekstah N. V. Gogolya: avtoref. dis. ... kand. filol. nauk. Special'nost' 10.01.01 / U.A. Kopenkina.-Saratov, 2011.-24 s.

Naumova, O.S. Formy vyrazheniya avtorskogo soznaniya v dramaturgii konca XX - nachala XXI vv. (na primere tvorchestva N. Kolyady i E. Grishkovca): avtoreferat dis. ... kand. filol. Nauk/ Special'nost' 10.01.01 / O. S. Naumova.- Samara, 2009.- 18 s.

Pronin, A. Strashnaya skazka o Peterburge / A. Pronin // Ekran i scena.-2017.31 marta. - URL: http://screenstage.ru/?p=6435 (data obrashcheniya: 5.11.2020). 
Pushkin, A. S. O narodnoj drame i drame «Marfa Posadnica» / A. S. Pushkin. Polnoe sobranie sochinenij: v 10t. T.VII: Kritika i publicistika.- Moskva: Nauka, 1964.- S. 211-221.

SHudegov, I. Piter kromeshnyj: Recenziya na spektakl' «SHinel' Gogolya». Predprem'era v teatr «CEKH»»/ / I. SHudegov // Plugged In.- 16.12.2018.- URL: https://pluggedin.ru/op/recenziya-na-spektakly-shinely-gogolya-predpremyera-v-teatrcehy-piter-kromeshnyy-13996 (data obrashcheniya: 01.12.2020).

Titova, E. V. Dramaturgicheskij paratekst: k postanovke problemy /E. V. Titova // Vestnik RGGU. Seriya: Literaturovedenie. YAzykoznanie. Kul'turologiya.- 2019.№ 2. - S. 30-40.

Voloshina, A. «Dramaturgiya - eto oprokinutyj psihoanaliz»: O zhizni posle osushchestvleniya mechty, akusticheskom teatre i kul'turnoj pamyati / A. Voloshina // Mnogobukv. Vsyo o creative writing / Novosti. 9 oktyabrya 2018.- URL: httpsmnogobukv-hse-ru-news-225501993-html (data obrashcheniya: 1.12.2020).

Voloshina, A. SHinel' Gogolya.-2016. -URL: http://mythos.spb.ru/?p=19 (data obrashcheniya: 5.11.2020).

ZHurcheva, O. V. Formy vyrazheniya avtorskogo soznaniya v «Novoj drame» rubezha H1H-HKH vekov / O.V. ZHurcheva // Kul'tura i tekst.-2001.-S.138-151.

Zu, YU. “CHelovek iz ryby" v MHT: Sneg na Karavannoj i vse-vse-vse /YU. Zu // MUSECUBE: territoriya tvorcheskoj svobody.- 12.03.2019.- URL: http://musecube. org/otchet/otchet-theatre/chelovek-iz-ryby-v-mht-sneg-na-karavannoj-i-vse-vse-vse/? fbclid=IwAR1f7ycBu65kjxBxCj2SX4TIcOvreYJj65Ut3EgR9NFUBFEz4Qf9Wtoov GU (data obrashcheniya: 01.12.20202).

Genette, G. Paratexte. Das Buch vom Beiwerk des Buches / G. Genette.Frankfurt/M: Suhrkamp, 2001.-401 s. 